\title{
Numerical simulation of seepage failure by upward flow considering internal erosion
}

\author{
S. Kimoto ${ }^{\text {i) }}$, T. Akaki ${ }^{\text {ii) }}$ H. Kodama ${ }^{\text {iii }}$ \\ i) Associate Professor, Department of Civil and Earth Resources Engineering, Kyoto University, Kyotodaigaku-katsura 4, Kyoto \\ 615-8540, Japan. \\ ii) Former Ph.D student, Department of Civil and Earth Resources Engineering, Kyoto University, Kyotodaigaku-katsura 4, Kyoto \\ 615-8540, Japan (presently in Technology Center, Taisei Corporation, Japan). \\ iii) Former student, Department of Civil and Earth Resources Engineering, Kyoto University, Kyotodaigaku-katsura 4, Kyoto 615-8540, \\ Japan.
}

\begin{abstract}
In the present study, seepage failure by upward flow is numerically simulated using a seepage-deformation coupled method in which the internal erosion of fine particles and the transport of these particles are considered. The field equations are derived in the framework of multiphase mixture theory, and the erosion process is modeled as the mass transfer from the solid phase to the fluidized soil phase. In addition, the particle size distribution of soil is considered in the erosion criteria and the rate equation of the mass transfer. Using the proposed method, one dimensional upward flow in a gap-graded sandy soil is simulated. From the simulations, it is found that the seepage failure occurs under relatively low average hydraulic gradient when the internal erosion is considered. This is due to the decrease in the total stress and the non-uniformity of hydraulic conductivity due to the erosion of fine particles.
\end{abstract}

Keywords: internal erosion, particle size distribution, numerical analysis

\section{INTRODUCTION}

Internal erosion is the detachment of fine soil particles due to seepage flow, with ensuing increasing porosity, and transport of these particles out of the soil mass. Progressive degradation of soil structure due to the internal erosion may lead to the local failure, such as, piping, and may result in cavities in the earth structures, such as earth dams, dikes and levees.

Recently, some numerical methods to predict soil erosion have been proposed, in which the constitutive laws of erosion, that is, the onset and the rate equations of the erosion are introduced into mathematical models in the framework of continuum mechanics (e.g., Steeb et al., 2004; Vardoulakis, 2004; Cividini et al., 2004; Wan and Wang 2004; Fujisawa et al. 2010; Uzuoka et al., 2012;). In the model, the fluidized soil particles are modeled as a fluid, and internal erosion is expressed by mass transition from soil skeleton to the additional fluid and migration of the fluidized soil particles.

In the following, the field equations to simulate hydro-mechanical behavior due to the internal erosion used in the present study (Akaki et al., 2016) are briefly presented. Then, the behavior of the proposed model is discussed with respect to seepage failure.

\section{NUMERICAL MODEL}

The field equations to simulate hydro-mechanical behavior due to the internal erosion were derived in the framework of multiphase mixture theory. The constituents are the soil particles $(S)$, the eroded soil particles or fluidized soil particles (FS), and the pore water $(W)$. It is assumed that the eroded soil particles moves unified with the pore fluid and the liquid phase $(L)$ is determined as $L=W+F S$ as shown in Fig. 1. The governing equations are the balances of mass for each phase, the balances of linear momentum for each phase, the constitutive model for soil skeleton and the erosion model. The constitutive equation for soil skeleton is of the elasto-viscoplastic type. Regarding the erosion criteria, it is assumed that the erosion takes place when the hydro-dynamical driving force acting on the small volume of mixture is larger than the resistance force over the area. The equations are spatially distretized by finite element method. The formulations of the numerical model proposed are presented in the following section. 


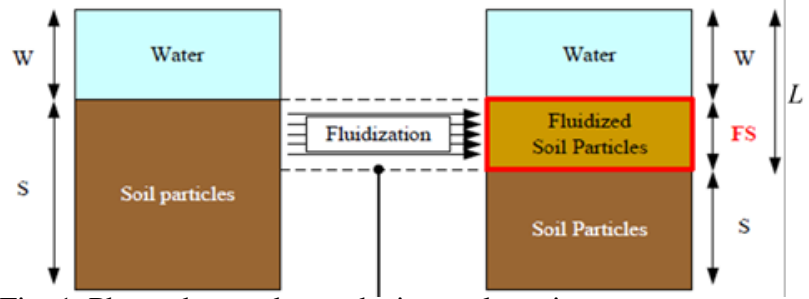

Fig. 1. Phase change due to the internal erosion.

\subsection{Definition of stress}

Firstly, the total stress tensor is the sum of the partial stress tensors of each phase as

$$
\sigma_{i j}=\sigma_{i j}^{S}+\sigma_{i j}^{W}+\sigma_{i j}^{F S}
$$

The partial stress tensors of each phase are defined as

$$
\begin{gathered}
\sigma_{i j}^{S}=\sigma_{i j}^{\prime}-n^{S} P \delta_{i j} \\
\sigma_{i j}^{L}=\sigma_{i j}^{W}+\sigma_{i j}^{F S}=-n P \delta_{i j}
\end{gathered}
$$

where $\sigma_{i j}^{S}, \sigma_{i j}^{W}$, and $\sigma_{i j}^{F S}$ are the partial stress tensors for the solid phase, the water phase, and the fluidized soil phase, respectively. $\sigma_{i j}^{\prime}$ is the effective stress tensor of the soil skeleton, $P$ is the pore pressure. It is assumed that the partial stress of the liquid phase, which is the sum of the partial stress of the water phase and the fluidized soil phase is given in Eq. (3). Substituting Eqs. (2) and (3) into Eq. (1) gives

$$
\sigma_{i j}^{\prime}=\sigma_{i j}+P \delta_{i j}
$$

Note that tension is positive for the stress tensor.

\subsection{Balances of linear momentum}

The equation of the balance of the linear momentum of the solid phase is given by

$$
\bar{\rho}^{S} \ddot{u}_{i}^{S}=\frac{\partial \sigma_{i j}^{S}}{\partial x_{j}}+\bar{\rho}^{S} b_{i}+R_{i}^{S L}
$$

where $\bar{\rho}^{S}=n^{S} \rho^{s}$ is the mass density of the solid phase $\left(n^{\alpha}\right.$ : volume fraction of $\alpha$ phase, $\rho^{\alpha}$ : mass density $\alpha$ phase), $\ddot{u}_{i}^{S}$ is the acceleration of the solid phase, $b_{i}$ is the body force vector, $R_{i}^{S L}$ is the interaction force term induced by the relative motion between the solid and fluid phase.

The equation of the balance of the linear momentum of the liquid phase is given by

$$
\bar{\rho}^{L} \ddot{u}_{i}^{L}=\frac{\partial \sigma_{i j}^{L}}{\partial x_{j}}+\bar{\rho}^{L} b_{i}-R_{i}^{S L}
$$

where $\bar{\rho}^{L}=n^{L} \rho^{L}$ is the mass density of the fluid phase, $n^{L}\left(=n^{W}+n^{F S}\right)$ is the volume fraction of the liquid phase, $\rho^{L}\left(=c \rho^{S}+(1-c) \rho^{W}\right)$ is the averaged mass density of the liquid phase, $\ddot{u}_{i}^{L}$ is the acceleration of the liquid phase. $c\left(=n^{F S} / n^{L}\right)$ is the concentration of the eroded soil particles in the liquid phase. The interaction term $R_{i}^{S L}$ in Eqs. (5) and (6) is proportional to the relative velocity between two phases and is given by

$$
\begin{gathered}
R_{i}^{S L}=n^{L} \frac{\rho^{L} g}{k} q_{i} \\
q_{i}=n^{L}\left(\dot{u}_{i}^{L}-\dot{u}_{i}^{S}\right)
\end{gathered}
$$

where $\dot{u}_{i}^{L}=\left(\dot{u}_{i}^{W}=\dot{u}_{i}^{F S}\right)$ is the velocity of the liquid phase, $\dot{u}_{i}^{S}$ is the velocity of the solid phase, $k$ is the hydraulic conductivity, $g$ is the gravity. The acceleration terms in Eqs. (5) and (6) are disregarded in the present study.

\subsection{Balances of mass}

The mass balance equation of each phase is given by

$$
\frac{\partial \bar{\rho}^{\alpha}}{\partial t}+\frac{\partial\left(\bar{\rho}^{\alpha} \dot{u}_{i}^{\alpha}\right)}{\partial x_{i}}=\dot{\rho}^{\alpha} \quad(\alpha=S, W, F S)
$$

where $\dot{\rho}^{\alpha}$ is mass change rate of $\alpha$ phase due to internal erosion. The advection equation of the fluidized soil particles is derived from the balance of mass of FS phase.

The void ratio dependency of the permeability is assumed to be given by Kozeny-Carman equation as

$$
k=k_{0} \frac{1+e_{0}}{1+e} \frac{e^{3}}{e_{0}^{3}}
$$

where $k_{0}$ is the initial hydraulic conductivity when the void ratio $e$ is the initial value of $e_{0}$.

\subsection{Erosion model}

It is assumed that the driving force of the internal erosion is given by the interaction force between solid and liquid phase in Eqs. (5) and (6) (Kimoto et al. 2017). The erosion takes place when the hydro-dynamical driving force acting on the small volume of mixture is larger than the resistance force over the area. as schematically shown in Fig. 2.

$$
R_{i}^{S L} n_{i} V_{g} \geq f_{1}\left(\sigma_{n}^{\prime}, \varepsilon^{p}, S\right) S_{g}
$$

where $V_{g}\left(=\pi D^{3} / 6 n^{s}\right)$ is the total volume around the soil particles, $S_{g}\left(=\pi D^{2}\right)$ and $S_{g}$ are the surface area over which acts the resistance force, $D$ is a 
diameter of soil particle, $n_{i}$ is the direction of the relative velocity of the liquid to the solid phase. The function $f_{1}$ is the resistance force per unit area which is considered to be a function of the effective stress $\sigma_{n}^{\prime}$ of solid phase, non-elastic strain $\varepsilon^{p}$, and other factor $S$ which may include the effect of suction for unsaturated seepage flow. Note that the present study is for the saturated seepage flow, and the erosion in unsaturated seepage flow will be the future study topic.

Considering that the direction of the vector $n_{i}$ coincides with that of $R_{i}^{S L}$, Eqs. (7) and (11) give the following equation:

$$
q \geq \frac{6 n^{s} k^{*}}{n^{L} \rho^{L} g} D=\frac{6 k^{*}}{e \rho^{L} g} D=q_{c r}
$$

where the hydraulic conductivity is assumed to be proportional to the square of the representative diameter of soil particle as $k=\tilde{k} D^{2}$. Due to a lack of experimental data for the resistance force, $k^{*}=\tilde{k} f_{1}$ is assumed in the present study. It should be noted that the critical flow rate $q_{c r}$ for the internal erosion is larger for the soil particle with larger diameter in Eq. (12) as schematically shown in Fig. 3.

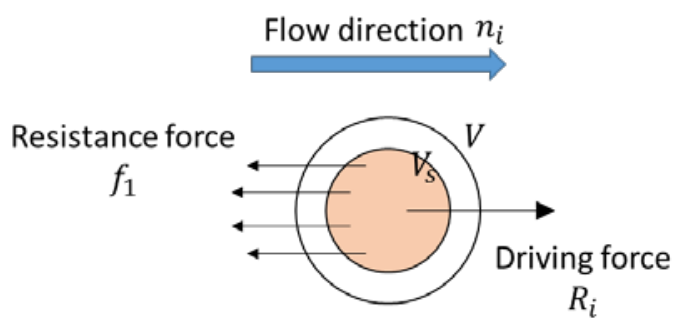

Fig. 2. Driving force and resistance force of internal erosion.

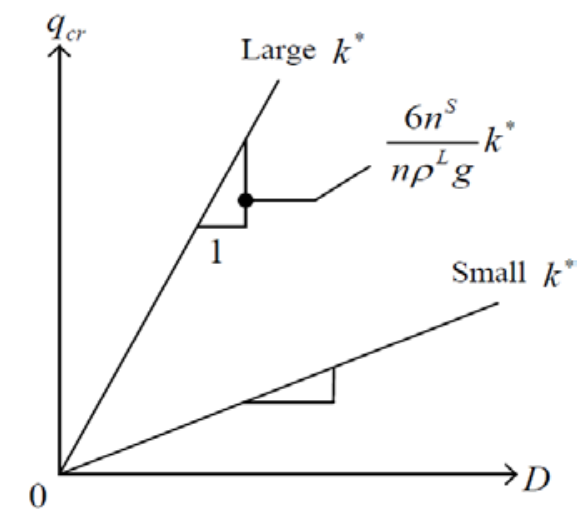

Fig. 3. Critical flow rate for soil particle with diameter $D$.

In the model, the soil mass is divided into several groups with the representative particle diameter of $D_{i}(i=1,2, \cdots N)$, and the erosion rate is given for each group as

$$
\dot{\rho}^{F S}\left(D_{i}\right)=-\dot{\rho}^{S}\left(D_{i}\right)
$$

$$
\begin{gathered}
=\alpha_{e r}\left\langle f_{2}\left(q\left(D_{i}\right)\right)\right\rangle \frac{m^{S}\left(D_{i}\right)-R m_{0}^{S}\left(D_{i}\right)}{m^{S}} \\
\begin{cases}\left\langle f_{2}\left(q\left(D_{i}\right)\right)\right\rangle=0 & \text { for } q>0 \\
\left\langle f_{2}\left(q\left(D_{i}\right)\right)\right\rangle=q-q_{c r} & \text { for } q>0\end{cases}
\end{gathered}
$$

where $m_{0}^{S}\left(D_{i}\right)$ and $m^{S}\left(D_{i}\right)$ are the initial and the current mass for the soil group of representative diameter $D_{i} . \alpha_{e r}$ is a material parameter of erosion rate, and $R$ is a material parameter of the ratio of the remaining particles.

\subsection{Constitutive model}

An elasto-viscoplastic model proposed by Kimoto and Oka (2015) which is based on the Perzyna's overstress type viscoplastic flow rule is adopted for the constitutive model of soil skeleton.

The governing equations are discretized in space by FEM. The unknowns are displacement of soil, pore water pressure, and the concentration of the eroded soil particles.

\section{SIMULATIONS}

\subsection{Simulation model and cases}

One dimensional upward flow is simulated. The height of the soil specimens is $300 \mathrm{~mm}$, and the water level of the water tank which is connected to the bottom of the model is increased by $240 \mathrm{~mm}$ in $2400 \mathrm{sec}$ as shown in Fig. 4. The average hydraulic gradient becomes 0.8 at 2400 sec. Finite element mesh and the boundary conditions are shown in Fig. 5 .

Gap-graded soil of the mixture of $70 \%$ of silica sand No. 3 and $30 \%$ of silica sand No. 8 is assumed. The particle size distribution curve is shown in Fig. 6. The material parameters for the constitutive are shown in Table 1, which are determined from the element simulation of drained triaxial tests (Ke and Takahashi, 2014) for the gap-graded sandy soil (Fig. 7).

Two simulations are conducted as shown in Table 2. Case 0 is the case without erosion in which the erosion rate parameter $\alpha_{e r}$ is set to be zero, and Case 1 is the case considering erosion. The erosion parameter $R=0$ is assumed in the present simulation.

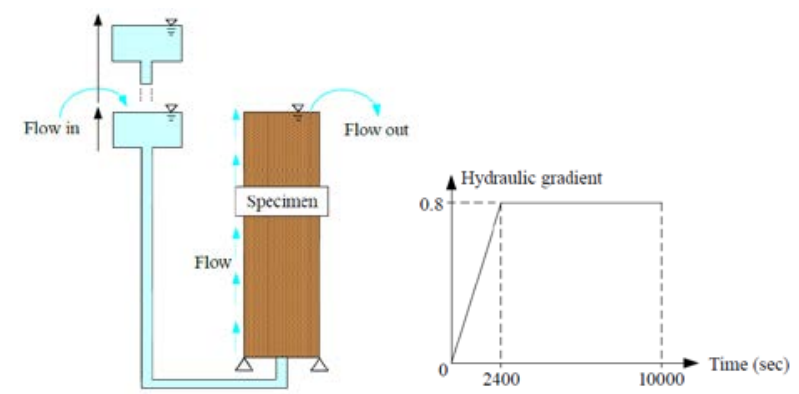

Fig. 4. Simulation model. 


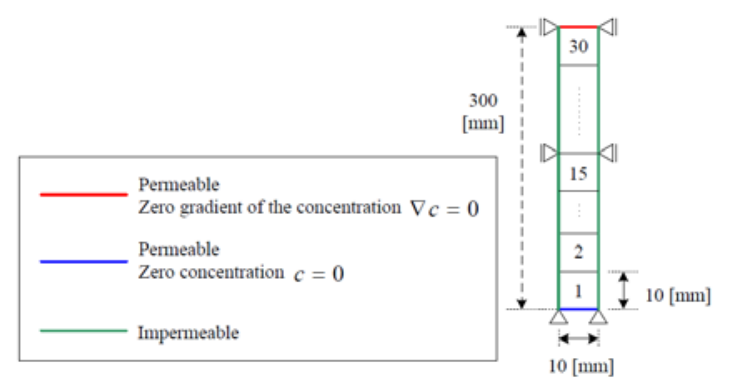

Fig. 5. Finite element mesh.

Table 1. Material parameters.

\begin{tabular}{lll}
\hline Compression and swelling index & $\lambda, \kappa$ & $0.053,0.005$ \\
\hline Normalized initial shear modulus & $G_{0}(\mathrm{kPa})$ & 2000 \\
\hline Initial void ratio & $e_{0}$ & 0.59 \\
\hline Quasi-Overconsolidation ratio & $O C R^{*}$ & 1.0 \\
\hline Viscoplastic parameter & $C_{1 r}, C_{2 r}(1 / \mathrm{s})$ & $1.0 \times 10^{-12}$ \\
\hline Viscoplastic parameter & $m^{\prime}$ & 40.0 \\
\hline Structural parameter & $\sigma_{m b f}^{\prime} / \sigma_{m b i}^{\prime}, \beta$ & $1.0,0.0$ \\
\hline Stress ratio at critical state & $M_{m}^{*}$ & 1.34 \\
\hline Referential hydraulic conductivity & $k_{0}(\mathrm{~m} / \mathrm{s})$ & $6.0 \times 10^{-5}$ \\
\hline
\end{tabular}

Table 2. Simulation cases (erosion parameters).

\begin{tabular}{lll}
\hline & $\alpha_{e r}\left(\mathrm{~kg} / \mathrm{m}^{4}\right)$ & $k^{*}\left(\mathrm{~kg} / \mathrm{m}^{4} / \mathrm{s}\right)$ \\
\hline Case 0 (without erosion) & 0.0 & $5.0 \times 10^{2}$ \\
\hline Case 1 (with erosion) & $1.0 \times 10^{4}$ & $5.0 \times 10^{2}$ \\
\hline
\end{tabular}

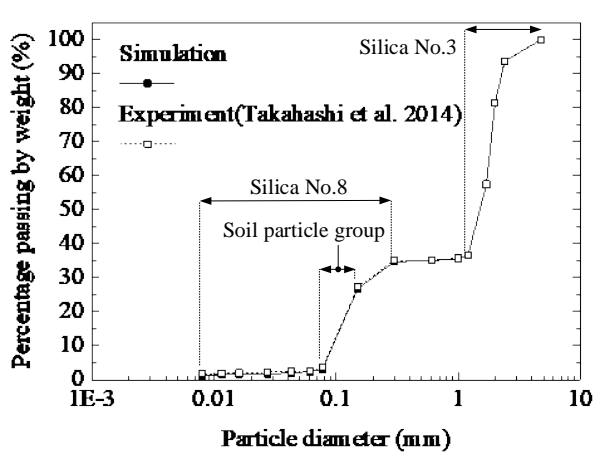

Fig. 6. Grain size distribution of gap-graded sandy soil.

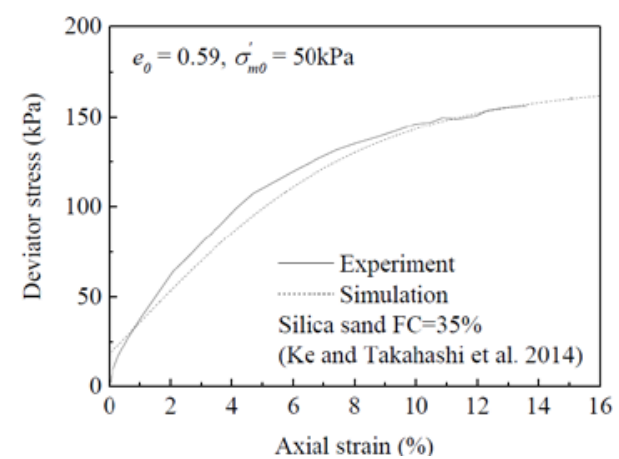

(a) Stress-strain relations

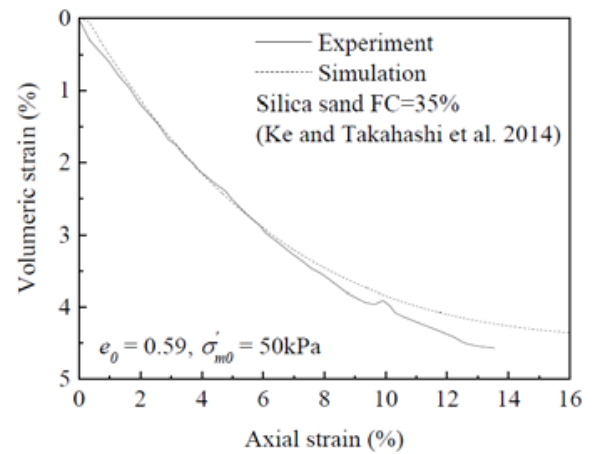

(b) Volumetric strain-axial strain relations Fig. 7. Determination of mataerial parameters (drained triaxial test).

\subsection{Results and discussions}

Fig. 8 shows the distributions of remaining soil mass and Fig. 9 shows the time-degree of remaning soil mass relations, which is defined by the ratio of current soil mass to the initial soil mass in each element, for Case 1. Fig. 9 shows that the erosion starts at around $1500 \mathrm{sec}$ in all the elements. This corresponds to the average hydraulic gradient of 0.5 . The erosion occurs homogeneously along the model until $2000 \mathrm{sec}$, and then the erosion proceeds faster for the upper element. The degree of remaining soil mass reaches 0.7 after $8000 \mathrm{sec}$, this means that all the fine particles, that is, silica sand No.8, are eroded. This behavior depends on the value of the erosion parameter $k^{*}$.

Figs. 10, 11, 12 show the distributions of the pore water pressure, the vertical total stress, and the vertical effective stress, respectively. Fig. 13 shows the time history of the effective stress decreasing ratio (ESDR) defined by $1-\sigma_{v}^{\prime} / \sigma_{v 0}^{\prime}$ in which $\sigma_{v 0}^{\prime}$ and $\sigma_{v}^{\prime}$ are the initial and the current vertical effective stress, respectively. The values of ESDR converge to 0.8 in Case 0 , where as they increase to around 1.0 , that is, seepage failure occurs in Case 1 . The hydraulic conductivity increases due to the increase of void ratio during erosion process as shown in Fig. 14.

From the simulations, the seepage failure occurs under lower average hydraulic gradient when the internal erosion is considered. This is mainly because of the decrease in the vertical stress. In addition, the non-uniformity of permeability due to the erosion of fine particles may lead to the failure due to the localized distribution of the hydraulic gradient.

\section{CONCLUSIONS}

One dimensional upward flow for gap-graded sandy soil was simulated using a seepage-deformation coupled analysis method in which the internal erosion of fine particles were considered. From the simulations, it is found that the seepage failure occurs under 
relatively low average hydraulic gradient when the internal erosion is considered due to the decrease in the total stress and the non-uniformity of hydraulic conductivity due to the erosion of fine particles.

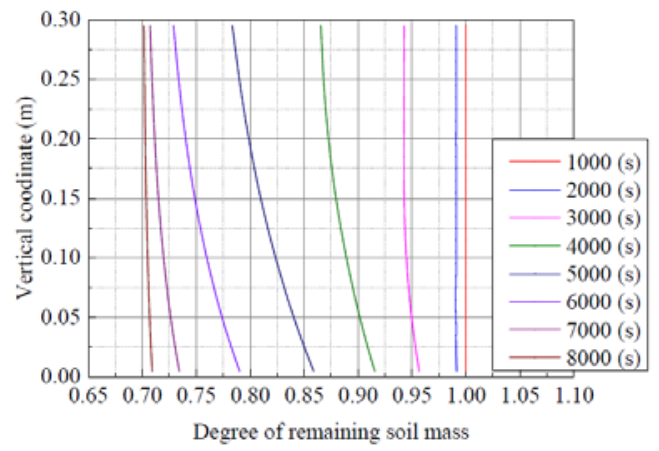

Fig. 8. Distributions of remaing soil mass (Case1).

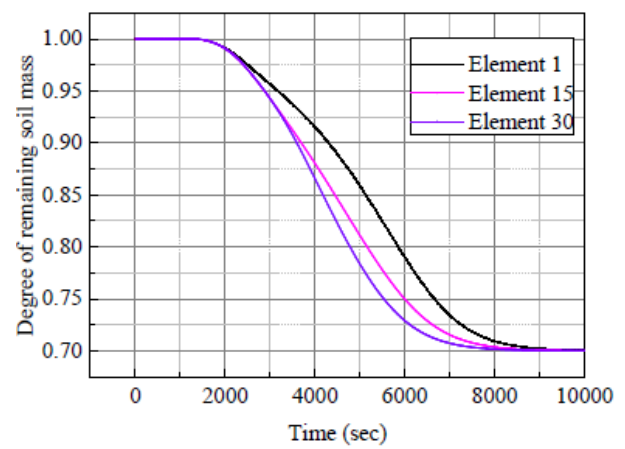

Fig. 9. Time-remaning soil mass relations (Case1).

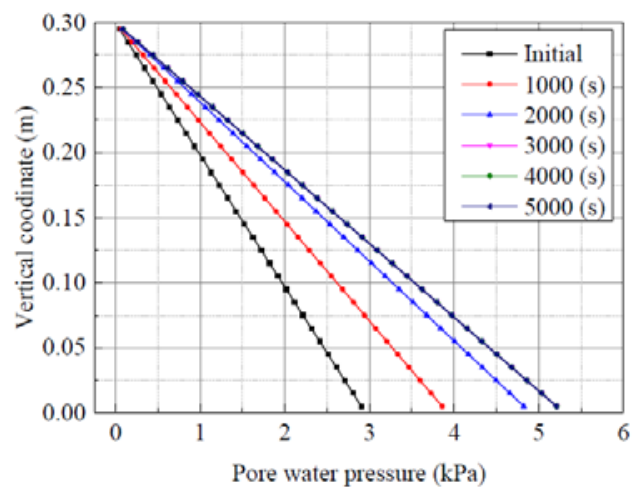

(a) Case 0

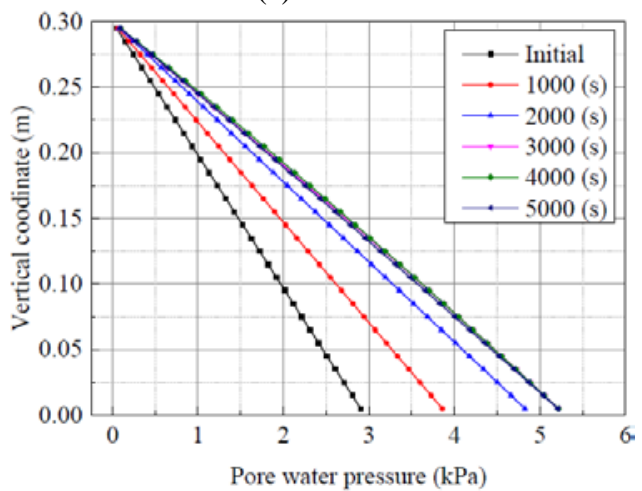

(b) Case 1

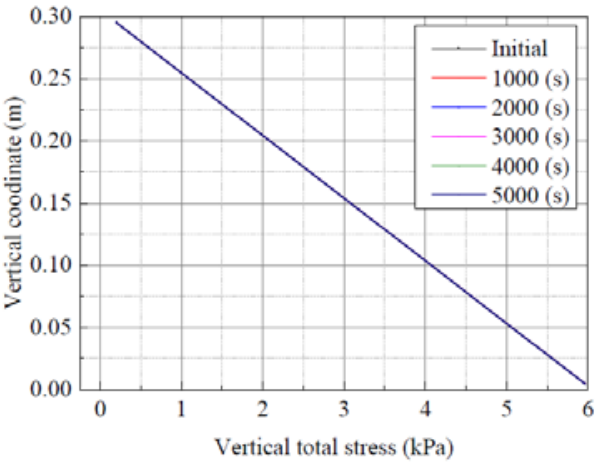

(a) Case 0

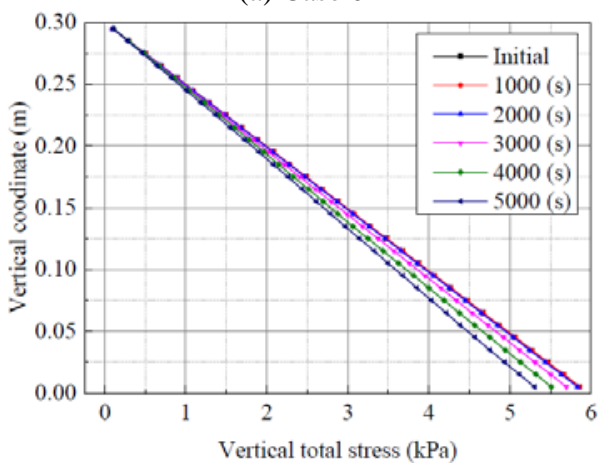

(b) Case 1

Fig. 11. Distributions of vertical total stress.

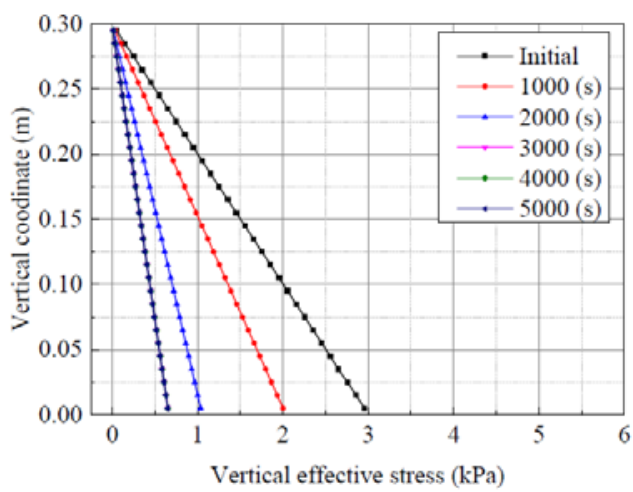

(a) Case 0

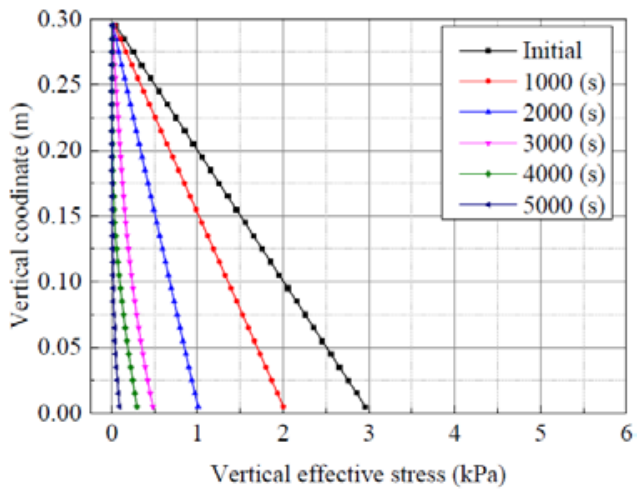

(b) Case 1

Fig. 12. Distributions of vertical effective stress.

Fig. 10. Distributions of pore water pressure. 


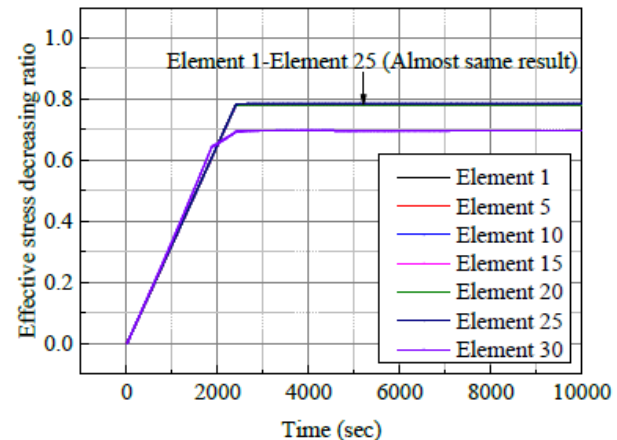

(a) Case 0

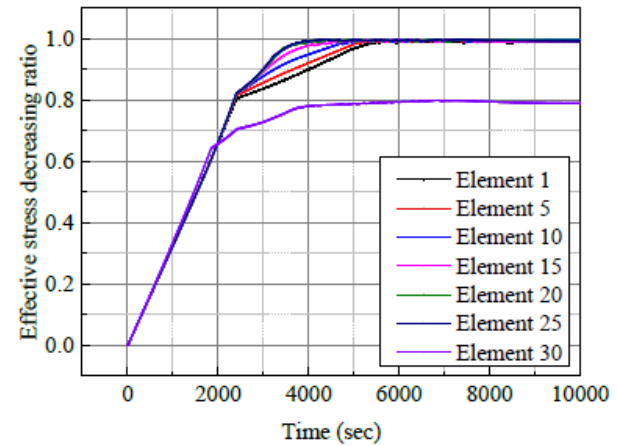

(b) Case 1

Fig. 13. Time-effective stress decreasing ratio relations.

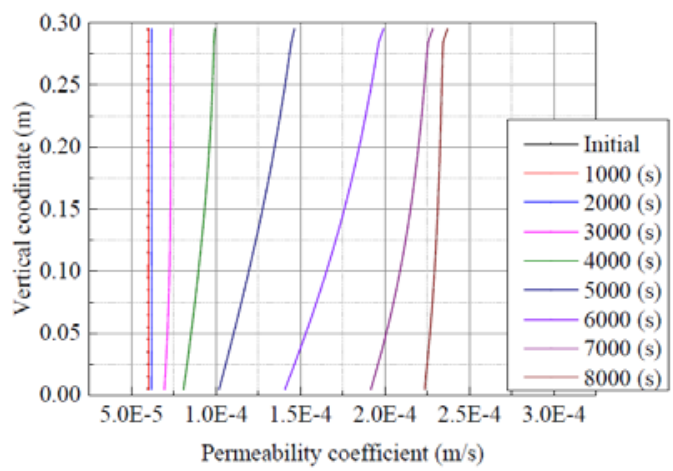

Fig. 14. Distributions of hydraulic conductivity (Case 1).

\section{REFERENCES}

1) Akaki, T., Aota, S., Kimoto, S., Oka, F. (2016): Numerical simulation of internal erosion by multiphase coupled analysis method, Journal of JSCE, 72 (2), I_75-I_86, 2016 (in Japanese).

2) Cividini A, Gioda G. (2004): Finite-element approach to the erosion and transport of fine particles in granular soils, International Journal of Geomechanics, 4 (3), 191-198.

3) Ke, L., and Takahashi, A. (2014): Experimental investigations on suffusion characteristics and its mechanical consequences on saturated cohesionless soil, Soils and Foundations, 54 (4), 713-730.

4) Kimoto, S., and Oka, F. (2005): An elasto-viscoplastic model for clay considering destructuralization and consolidation analysis of unstable behavior. Soils and Foundations, 45 (2), 29-42.

5) Kimoto, S., Akaki, T., Loret, B., Oka, F. (2017): A numerical model of internal erosion for multiphase geomaterials, bifurcation and degradation of geomaterials with engineering applications, Proc. of the 11th IWBDG, Limassol, Cyprus, 21-25 May 2017, Springer Series in Geomechanics and
Geoengineering, 125-131.

6) Steeb H, Diebels S, Vardoulakis I. (2004): A multiphase continuum-based model capturing erosion and deposition, International Symposium on Trends in Application of Mathematics to Mechanics, STAMM 2004, Seeheim, Germany, 519-528.

7) Uzuoka R, Ichiyama T, Mori T, Kazama M. (2012): Hydro-mechanical analysis of internal erosion with mass exchange between solid and water, 6th International Conference on Scour and Erosion 2012; Paris, France, 655-662.

8) Vardoulakis I. (2004): Fluidisation in artesian flow conditions: Hydromechanically stable granular media, Geotechnique, 54 (2), 117-130.

9) Wan RG. Wang J. (2004): Analysis of sand production in unconsolidated oil sand using a coupled erosional-stress-deformation model, Journal of Canadian Petroleum Technology, 43(2), 47-53. 